\title{
The Effect of Short Duration Isometric and Dynamic Exercises on Pain Threshold in Healthy Young Females
}

\author{
SAMIHA M. ABELKADER, M.D., Ph.D. \\ The Department of Rehabilitation Health Sciences, College of Applied Medical Sciences, King Saud University, \\ Kingdom of Saudi Arabia
}

\begin{abstract}
Background: Musculoskeletal pain is a common problem encountered in medical practice. Exercise canprovidet emporary relief from pain. Hypoalgesia is found to occur during and after single episodes of high intensity aerobic exercise in healthy adults. However, not all individuals are willing or able to engage in high-intensity aerobic exercise.
\end{abstract}

Aim of Study: To examine the character of pain threshold modulation that occurs following short-duration isometric and dynamic exercises.

Material and Methods: Eighty healthy female students of College of Applied Medical Sciences, King Saud University, age ranged between 18 and 23 years participated in study. The sample was divided randomly into two equal groups; first group was tested for the effect of isometric exercise on pressure pain threshold and the second group was tested for the effect of dynamic exercise on pain threshold.

Results: Results indicated that there were significant effects for both isometric and dynamic exercises on pain threshold which was found to be elevated in both exercised and non-exercise dsides after isometric and dynamic exercises and lasted for ten minutes.

Conclusion: It was concluded that short duration nonexhaustive isometric and dynamic exercises was associated with hypoalgesic responses in ipsilateral and contralateral sides in healthy young females.

Key Words: Isometric exercise - Dynamic exercise - Pain threshold.

\section{Introduction}

MUSCULOSKELETAL pain is a common problem encountered in medical practice. It is estimated that over one-third of the world's population suffers from persistent or recurrent pain either associated with advanced illness or other acute or chronic conditions [1]. Although physicians now have very effective treatments at their disposal, pain remains

Correspondence to: Dr. Samiha Abdelkader, E-Mail: sabdelkader@ksu.edu.sa one of the most poorly assessed and treated physical symptoms [2].

In terms of pain perception, thresholds for feeling pain are remarkably constant among all individuals (i.e. Peripheral receptor stimulation of sufficient intensity will reproducibly cause pain at the same level in most people). The response of the individual, and his tolerance of the pain, will however differ markedly between individuals. The sensory level (intensity) required for detection (pain threshold) is rather constant, whereas the intensity level required to elicit spontaneous complaints (tolerance "threshold") is highly variable [3]

Isometric exercise has been shown to provide temporary relief from pain, it may have clinical utility as a method for pain management. There are many studies that showed the relationship between pain threshold and exercise. These studies provided a good base in physical therapy field to use the benefits of post-exercise analgesia [4-7].

In general, hypoalgesia found to occur during and after single episodes of high intensity aerobic exercise in healthy young adults [5]. This has been characterized by elevations in pain thresholds, elevations in pain tolerances, as well as reductions in pain intensity ratings during and after exercise. Not all individuals, however, are willing or able to engage in high-intensity aerobic exercise; thus, it would seem important to determine whether other forms of exercise (e.g. dynamic resistance exercise, isometric exercise) are associated with alternation on pain threshold hence, hypoalgesia response.

The primary aim of this study was to examine the pain threshold modulation that occurs following different types of exercise (isometric and dynamic). 
The secondary aim was to compare the postexercise pain threshold between the dominant and non-dominant side and to determine the relationship between pain threshold and the degree of muscle strength.

\section{Material and Methods}

Study design: This was a cross sectional Comparative study. Eighty healthy female students between the ages of 18-23 years (mean age 20.8 S.D. years) wer erecruited from the College of Applied Medical Sciences (CAMS), King Saud University (KSU), Riyadh, Saudi Arabia. The study was conducted during the period between March 2018 and May 2019. The studentshaving pregnancy, obesity, medical problems, neurological problems like sensory or motor disturbance and traumatic lesion of head or upper limbs (sprain, strain) for at least two months before conduction of the study were excluded. The participants were randomly and equally assigned into two groups: The Isometric Exercise (IE) group and the Dynamic Exercise (DE) group.

\section{Procedures:}

This study was conducted at the physiotherapy laboratory at the Department of Rehabilitation, CAMS, KSU. The study received approval from the Research committee of the College. All subjects signed consent form to participate. Weight and height were recorded and BMI was calculated to exclude obese subjects. History was taken from all subjects about previous illnesses, medications and/or any clinical conditions. The participants were asked to stop any regular exercise one weekbefore each visit.

\section{Instruments:}

Handheld dynamometer (Preston, 07012, New Jersey) was used as an exercise resistance, whereas a dolorimeter (Baseline, 56217, Danbury) was used to assess the Pressure Pain Threshold (PPT). The application of the dolorimeter and dynamometer were explained to participants and both instruments were tried on them without actually taking measurements. The PPT test was conducted with participant seated with dominant arm resting at 900 of elbow flexion in supinated position. The dolorimeter was vertically pressed onto to the dorsal aspect of forearmof both hands. The rate of applied force was approximately $2 \mathrm{lb}$. Eachparticipant was instructed to verbally indicate when the gradually increasing applied pressure turned into pain perception. The pain causing force was recorded.
Data was collected at two different sessions. During the first visit, Maximum Dominant Hand Grip Strength (MDHGS) and resting PPT were tested. The MDHGS were tested by a handheld dynamo meter (three tests were taken with ten minutes of rest between them) then the maximum result was recorded as MDHGS. The resting PPT of each participant was tested by a dolorimeter to determine a baseline. They sat quietly in laboratory for seven minutes in a comfortable back-arms chair. The participant was prepared for the dolorimeter application by marking a small one $\mathrm{cm}$ radius circle on the forearms (seven cm distally to cubital fossa and $1 \mathrm{~cm}$ medially to the forearm midline. The Applied Force Pain Threshold (AFPT), by the dolorimeter, was obtained 30s after rest period, in both dominant and non-dominant forearms. Thedolorimeter application was repeated three times (over the original marking, one $\mathrm{cm}$ above it and one $\mathrm{cm}$ below) and a mean of these three applied pressure measurements wasrecorded.

In second visit, after 2 days, post exercise PPT was estimated for both isometric and dynamic exercises groups after application of the specific exercise for each group:

Isometric exercise for $G 1$ :

This contraction (40\%-50\%) was calculated by using previous MDHGS then range (40\%-50\%) was marked on the dynamo meter and participant was asked not to proceed out of the range during squeezing. The participant was asked to dosub maximal contraction by consistently squeezing on dynamometer by their dominant hand for $60 \mathrm{sec}-$ onds. Immediately after releasing, Dolorimeter pressure force was applied to measure the PPT, in both dominant and non-dominant forearms, after the isometric exercise. The dolorimeter measurements were also taken $1 \mathrm{~min}, 5 \mathrm{~min}$, and $10 \mathrm{~min}$ after exercise for both sides [11].

\section{Dynamic exercise for $G 2$ :}

This contraction (40-50\%) was calculated by using the previous MDHGS then the range (40$50 \%$ ) was marked on the dynamometer and participant was asked not to proceed out of the range during squeezing. The participant was asked to do the sub maximal contraction by squeezing on the dynamometer by their dominant hand and releasing it respectively for 60 seconds. Immediately after the last release, Dolorimeter pressure force was applied to measure the PPT, in both dominant and non-dominant forearms after the dynamic exercise. The dolorimeter measurements were also taken $1 \mathrm{~min}, 5 \mathrm{~min}$, and $10 \mathrm{~min}$ after the exercise from both sides [4] 


\section{Statistical analysis:}

The Shapiro-Wilk test was used to seen or mality of the data. Descriptive statistics were done to assess the demographic variables and further analysis was done using paired $t$-test and independent $t$-test. The level of significance was set at 0.05 .

\section{Results}

Table (1) shows mean values of PPT modulation associated with isometric exercise group. There was a significant increase in PPT after isometric exercise in the exercised hand $(p<0.05)$. The mean PPT was $4.90 \pm 1.31$ before the isometric exercise and $7.39 \pm 1.99$ immediately after the exercise. Also, there was a significant increase in PPT after 10 minutes of stopping the isometric exercise in the exercised hand $(p<0.05)$. The mean PPT was 7.23 \pm 2.00 after 10 minutes of stopping the isometric exercise.

There was also a significant increase in PPT $(6.73 \pm 1.68)$ after isometric exercise in nonexercised hand $(p<0.05)$. There was a significant increase in PPT $(6.80 \pm 2.21)$ after 10 minutes of stopping the isometric exercise in non-exercised hand $(p<0.05)$.

Table (1): PPT modulation associated with isometric exercise group.

\begin{tabular}{lccc}
\hline Variables & $\begin{array}{c}\text { Isometric } \\
\text { group }\end{array}$ & $\begin{array}{c}\% \\
\text { change }\end{array}$ & $\begin{array}{c}p^{-} \\
\text {value }\end{array}$ \\
\hline $\begin{array}{l}\text { - Pre-exercise dominant hand PPT } \\
\text { - Post exercise dominant hand PPT } \\
\quad \text { (immediate) }\end{array}$ & $\begin{array}{l}4.90 \pm 1.31 \\
7.39 \pm 1.99\end{array}$ & 50.28 & $<0.05^{*}$ \\
- Pre-exercise dominant hand PPT & $4.90 \pm 1.31$ & 47.5 & $<0.05^{*}$ \\
- Post exercise dominant hand PPT & $7.23 \pm 2.00$ & & \\
$\quad$ (1 0min) & & & \\
- Pre-exercise non-dominant hand PPT & $4.71 \pm 1.34$ & 42.8 & $<0.05^{*}$ \\
- Post-exercise non-dominant hand & $6.73 \pm 1.68$ & & \\
$\quad$ PPT (immediate) & & & \\
- Pre-exercise non-dominant hand PPT & $4.71 \pm 1.34$ & 44.3 & $<.0 .05^{*}$ \\
- Post-exercise non-dominant hand & $6.80 \pm 2.21$ & & \\
$\quad$ PPT (10min) & & & \\
\hline
\end{tabular}

Table (2) shows mean values of PPT modulation associated with dynamic exercise group. There was a significant increase in PPT after dynamic exercise in exercised hand $(p<0.05)$. The mean PPT was $5.20 \pm 1.35$ before the dynamic exercise and $7.02 \pm 2.19$ immediately after the exercise. Also, there was a significant increase in PPT after 10 minutes of stopping the dynamic exercise in the exercised hand $(p<0.05)$. The mean PPT was 7.26 \pm 2.34 after 10 minutes of stopping the dynamic exercise.

Table shows that there was a significant increase in PPT after dynamic exercise in the non-exercised hand $(p<0.05)$. The mean PPT was $4.99 \pm 1.18$ before the dynamic exercise and $6.84 \pm 2.00$ immediately after the exercise. Also, there was a significant increase in PPT after 10 minutes of stopping the dynamic exercise in the non-exercised hand $(p<0.05)$. The mean PPT was $6.87 \pm 2.05$ after 10 minutes of stopping the dynamic exercise.

Table (2): PPT modulation associated with dynamic exercise group.

\begin{tabular}{lccc}
\hline Variables & $\begin{array}{c}\text { Isometric } \\
\text { group }\end{array}$ & $\begin{array}{c}\% \\
\text { change }\end{array}$ & $\begin{array}{c}p \text { - } \\
\text { value }\end{array}$ \\
\hline - Pre-exercise dominant hand PPT & $5.20 \pm 1.35$ & 35 & $<0.05^{*}$ \\
- Post exercise dominant hand PPT & $7.02 \pm 2.19$ & & \\
$\quad$ (immediate) & & & \\
- Pre-exercise dominant hand PPT & $5.20 \pm 1.35$ & 39.6 & $<.0 .05^{*}$ \\
- Post exercise dominant hand PPT & $7.26 \pm 2.34$ & & \\
$\quad$ (1 Omin.) & & & $<0.05^{*}$ \\
- Pre-exercise non-dominant hand PPT & $4.99 \pm 1.18$ & 37 & \\
- Post exercise non- dominant hand & $6.84 \pm 2.00$ & & \\
$\quad$ PPT (immediate) & & & \\
- Pre-exercise non-dominant hand PPT & $4.99 \pm 1.18$ & 37.6 & $<0.05^{*}$ \\
- Post exercise non-dominant hand & $6.87 \pm 2.05$ & & \\
$\quad$ PPT (10min.) & & & \\
\hline
\end{tabular}

*: Significant at $p<0.05$.

Table (3) shows comparison of the mean value of PPT modulation between the isometric exercise group and the dynamic exercise group. There was no significant difference in the effect of the isometric and dynamic exercises $(p>0.05)$. The mean value of PPT was $7.39 \pm 1.99$ after the isometric exercise and $7.02 \pm 2.19$ after the dynamic exercise.

Table (3): Comparison of PPT modulation between the isometric exercise group and the dynamic exercise group.

\begin{tabular}{lccc}
\hline Variables & $\begin{array}{c}\text { Isometric } \\
\text { group }\end{array}$ & $\begin{array}{c}\text { Dynamic } \\
\text { group }\end{array}$ & $\begin{array}{c}p \text { - } \\
\text { value }\end{array}$ \\
\hline - Post exercise dominant hand PPT \\
$\begin{array}{l}\text { (immediate). } \\
\text { (imment.39 }\end{array}$ & & $7.02 \pm 2.19$ & $>0.05$ \\
\hline
\end{tabular}

*: Significant at $p<0.05$.

Table (4) shows the relationship between the PPT and the degree of muscle strength. There was no significant relationship between PPT and the degree of muscle strength ( $r=0.143)$ and $(p>0.05)$.

Table (4): The relationship between the PPT and pain the degree of muscle strength.

\begin{tabular}{lcr}
\hline Variables & Correlation & $p$-value \\
\hline Max. Dominant hand grip strength & 0.134 & $>0.05$ \\
PPT & & \\
\hline
\end{tabular}

*: Significant at $p<0.05$.

\section{Discussion}

The results of the current study showed that there was a significant increase in PPT after isometric exercise in both dominant and non-dominant 
hands. There was also a significant increase in PPT after 10 minutes of stopping the isometric exercise in both the hands. The study results are in line with the Bement, et al. [8] study which evaluated the response of isometric contractions on pain perception in healthy adults. They found that low-intensity isometric contractions produced an analgesic response. The greatest change in pain threshold and pain ratings, when pressure was applied to the contralateral finger, was after the long-duration, low-intensity contraction sustained after sometime. Another study by Ylinen et al., [9] also showed that both isometric and dynamic neck muscle exercises diminish neck pain by two ways, raising pain threshold and lowering sensitivity to pain.

Kosekand Lundberg [5] studied twenty-four healthy subjects (12 females, 12 males) and performed a standardized isometric contraction with the dominant muscles; quadriceps femoris and infraspinatus. During contraction of both muscles PPTs increased compared to baseline at the middle and the end of the contraction period at all assessed sites. The increase was more pronounced at the contracting muscle compared to the contralateral and the distant sites. Following the contractions PPTs returned to baseline. Submaximal isometric contraction gave rise to a statistically significant increase in PPTs at the contracting muscle, the resting homologous contralateral muscle and at the distant resting muscle. This shows that the overall pain inhibitory mechanisms were activated. Contraction of in fraspinatus, but not of quadriceps femoris gave rise to an additional activation of unilateral segmental antinociceptive response. The study findings showed that effect of exercise is seen on non-exercised arm. This is supported by a study conducted using two types of exercises [10]. They examined if any differences existed in the exercise-induced hypoalgesia of Isometric Gripping Exercise (IGE) and Treadmill Exercise (TE). They also showed that effect of exercise is not confined to only the exercised side, but the effect reaches the contralateral side.

The current study included young females and the results showed exercise induced hypoalgesia after a short bout of exercise. Similar to the current study findings, a study conducted by Koltyn and Umeda [4] to examine whether exercise induced hypoalgesia occurred in women after short-duration submaximal isometric exercise and whether the responses were restricted to the exercised hand (ipsilateral) or also occurred in the nonexercised (contralateral) hand. They found that there were significant trials effects for Pain Threshold (PT) and Pain Rating (PR), but the main effect for hands was not significant. PTs were found to be elevated, whereas PRs were reduced for both hands after isometric exercise. The findings from this study demonstrated that short-duration non-exhaustive isometric exercise was associated with hypoalgesic responses in the exercised and non-exercised hands. It appears that short-duration submaximal isometric exercise resulted in generalized (i.e, ipsilateral and contralateral) pain-inhibitory responses in healthy young women. The results of this study indicated that there is significant effect for both isometric and dynamic exercises on PPT. PPTs were found to be elevated in both exercised and non-exercised sides after isometric and dynamic exercises and lasted for ten minutes. The results also showed that there is no difference between the effect of isometric exercise and the dynamic exercise on PPT.

\section{Conclusion:}

The conclusion of the study was that short duration non-exhaustive isometric and dynamic exercise are associated with hypoalgesic responses in ipsilatral and contralateral sides in healthy young females.

Acknowledgment: I would like to sincerely thank all the participants for accepting to be a part of the study.

\section{References}

1- LOESER J.D., BUTLER S.H., CHAPMAN C.R. and TURK K.C.: Bonica's Management of Pain. ed: 2001, Lippincott, Philadelphia, 2001.

2- EMANUEL L.L., VON GUNTEN C.F. and FERRIS F.D.: The Education for Physicians on End-of-life Care (EPEC) module 4 (pain management), the robert wood johnson foundation, 1999.

3- FIELDS H.L. and LEVINE J.D.: Pain-Mechanisms and Management. Medical Progress, 1984.

4- KOLTYN K.F. and UMEDA M.: Contralateral attenuation of pain after short-duration submaximal isometric exercise. J. Pain, 11: 887-9, 2007.

5- EVA KOSEK and LENA LUNDBERG: Segmental and plurisegmental modulation of pressure pain thresholds during static muscle contractions in healthy individuals. Euro J. Pain, 7: 251-8, 2003.

6- KOLTYN K.F. and ARBOGAST R.W.: Perception of pain after resistance exercise. Br. J. Sports Med., 32: 20-4, 1998.

7- GHIONE S.: Hypertension-associated hypalgesia: Evidence in experimental animals and humans, pathophysiological mechanisms, and potentialclinical consequences. Hypertension, 28: 494-504, 1996.

8- HOEGER BEMENT M.K., DICAPO J., RASIARMOS R. and HUNTER S.K.: Dose response of isometric contractions on pain perception in healthy adults. Med. Sci. Sports Exer., 40: 1880-9, 2008. 
9- JARI YLINEN, ESA-PEKKA TAKALA, HANNU KAUTIAINEN, MATTI NYKÄNEN, ARJA HÄKKINEN, TIMO POHJOLAINEN, SIRKKA-LIISA KARPPI and OLAVI AIRAKSINEN: Effect oflong term neck muscle training on pressure pain threshold: A randomized controlled trial. Euro J. Pain, (9): 673-81, 2005.

10- DANIEL G. DRURY, KRISTIN STUEMPFLE, ROBIN
SHANNON and JAMES MILLER: An Investigation of Exercise-Induced Hypoalgesi After Isometric And Cardiovascular Exercise.An International Electronic Journal, 7: 1-5, 2004.

11- HOEGER BEMENT M.K., DICAPO J., RASIARMOS R. and HUNTER S.K.: Dose response ofisometriccontractions on pain perception in healthy adults. Med. Sci. Sports Exerc., 40: 1880-9, 2008.

\section{تآثير تمارين قصيرة المدى الساكنة والديناميكية

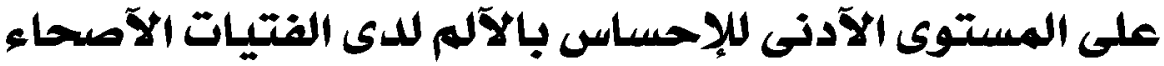

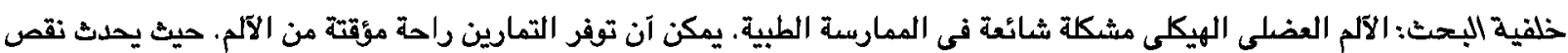

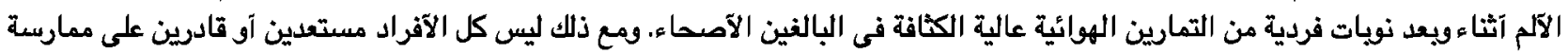

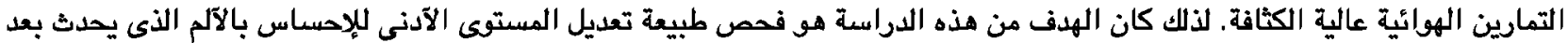

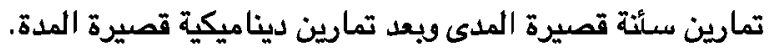

الطريقة: شارك فى الدراسة ثمانون طالبة يتمتعن بصحة جيدة من كلية العلوم الطبية التطبيقية بجامعة الملك سعود تراوحت آعمارهن

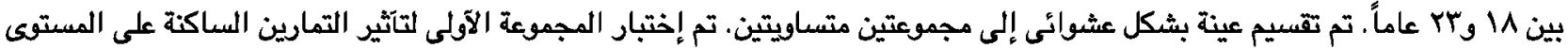
الآدنى للإحساس بالآلم وتم إختبار المجموعة الثانية لتَّتير التمارين الديناميكية على المستوى الآدنى للإحساس بالئي الآلم.

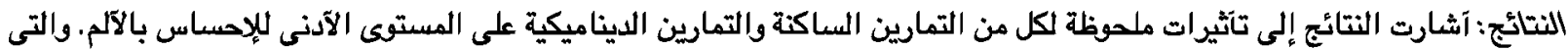

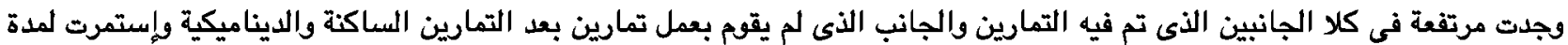
عشر دقائق. الخلاصة: التمارين قصيرة المدى الغير مجهدة الساكنة والديناميكية تحسن إستجابة الإحساس بنقص الآلم فى نفس الجانب والجانب المقابل فى الإناث الشابات الآصحاء. 